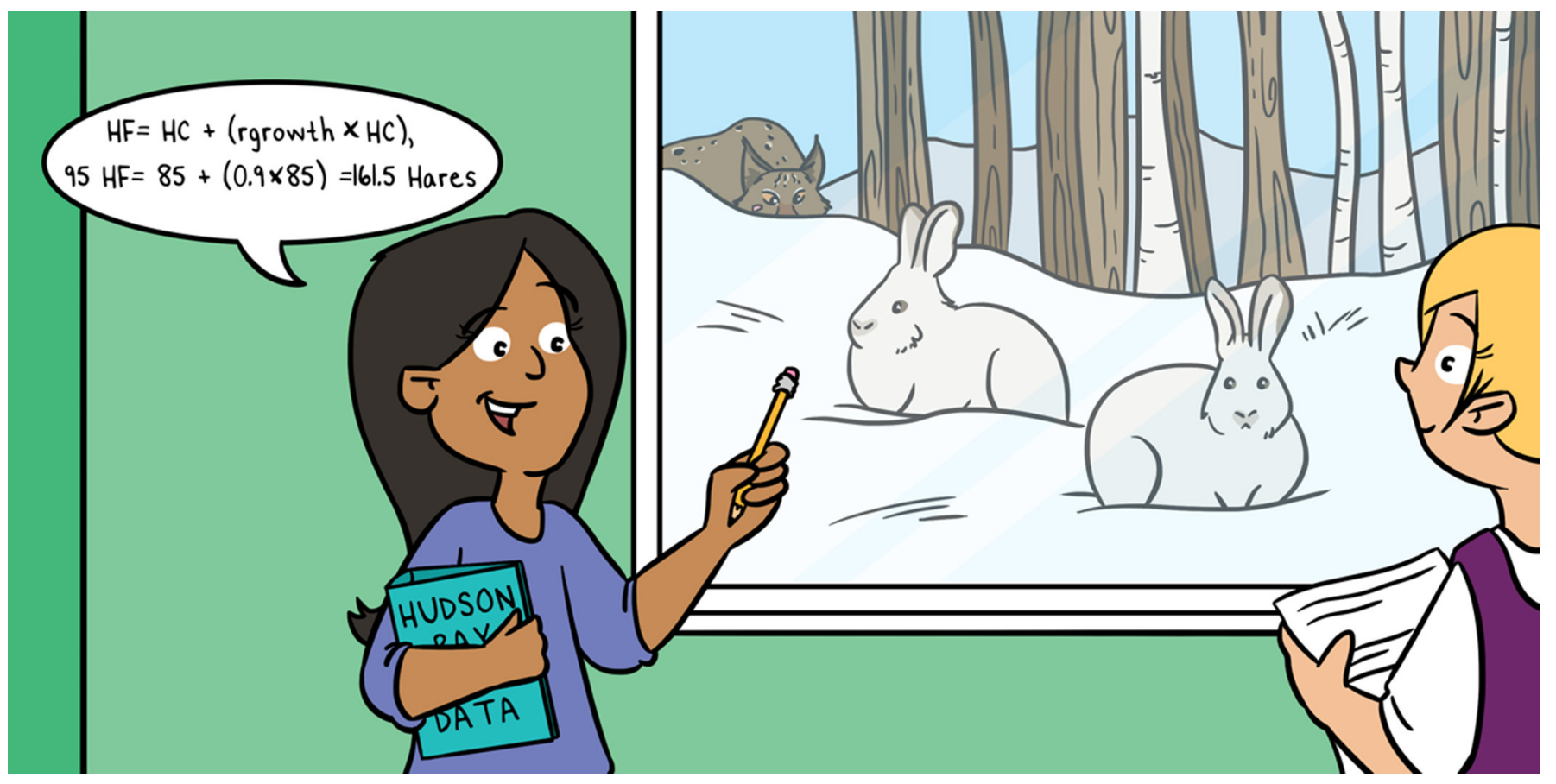

\title{
THE CIRCLE OF LIFE: THE MATHEMATICS OF PREDATOR-PREY RELATIONSHIPS
}

\section{Rebecca M. Brady ${ }^{1,2 t}$ and John S. Butler ${ }^{1,2^{* t}}$}

${ }^{1}$ School of Mathematical Sciences, Technological University Dublin, Dublin, Ireland

${ }^{2}$ ESHI (Environmental Sustainability and Health Institute), Technological University Dublin, Dublin, Ireland

YOUNG REVIEWERS:

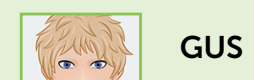

AGE: 11

(बन JOSIAH

AGE: 11
Some animals hunt other animals to feed themselves; these animals are called predators. Animals who are hunted and eaten are known as prey. What do you think would happen if a predator were introduced to an ecosystem where the prey previously lived without fear of being hunted? Would the new predator eat all the prey animals until they go extinct? Actually, the relationship between predator and prey is far more interesting than this. In this article, we show what the predator-prey relationship looks like over time and explain how scientists can make predictions about future population levels, all using basic mathematics like addition, subtraction, and multiplication.

\section{WHY DO WE STUDY ANIMAL POPULATIONS?}

Scientists need to collect information so they can understand how to protect the environment and the animals who live there. Scientists sometimes use mathematics to test theories they have about the animals or even to try to predict the future! This is called mathematical 
Figure 1

(A) The number of hare pelts collected (in tens of thousands) over time. (B) The number of lynx pelts collected (in tens of thousands) over time, inferred from Hudson Bay Company data from 1895 to $1935^{1}$

1 Link to animated version of the figure here.
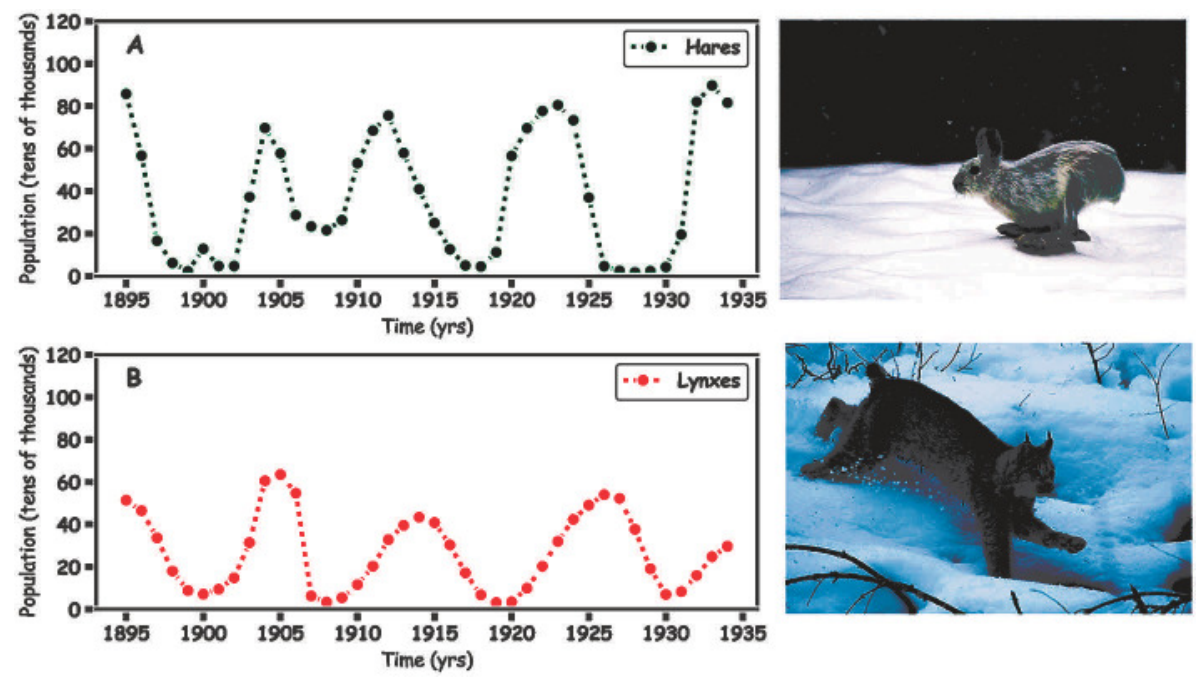

Figure 1

modelling. Modelling the relationship between predators and prey helps scientists understand how their populations change over time, and it can let scientists know when an animal could be at risk of extinction. To make a successful mathematical model, we need to collect data from the environment. In this paper we will show how some basic mathematics, like addition, subtraction, and multiplication, can be used to model the predator-prey relationships seen in the wild.

\section{FIRST, WE NEED DATA!}

Good models start with good data. To model a predator-prey relationship, we will use population data (records of how many animals there are) collected by a company that hunted both the predators and prey for their fur in the nineteenth and twentieth centuries. The Hudson Bay Company made yearly records of the numbers of snow lynx and snowshoe hare pelts they collected. Figure 1 shows the company's data for the number of hare and lynx pelts. The number of hare or lynx pelts collected tells us about the levels of each animals' population and can give us a reasonable picture of the predator-prey relationship. The data show that in some years, like 1927, there were more lynxes (predators) but fewer hares (prey), while in other years, like 1932, there were more hares but fewer lynxes.

\section{WHAT DOES THE HUDSON BAY DATA TELL US?}

The rise and fall in the recorded hare and lynx populations over time suggests that there is a relationship between the two animals, which makes sense as we know that lynxes eat hares. In Figure 1, can you see that the populations of lynxes and hares fall and rise at around 


\section{DIFFERENTIAL EQUATIONS}

Equations that describe how populations change over time, or describe many other processes, including how a helicopter flies, how planets orbit a star, or how blood flows in our veins.

\section{ESTIMATE}

$A$ value that is close enough to the exact answer, usually created based on some knowledge you have of the system or by preforming a calculation.

\section{GROWTH RATE}

The growth rate is the increase of the hare population if they had no predators. It can be estimated from the data using the number of births minus deaths.

\section{DEATH RATE}

The death rate is the decrease of the lynx population over time if they had no food. This is the number of deaths minus births.

\section{EAT RATE}

The eat rate is the number of hares hunted and eaten by the lynx.

\section{FOOD RATE}

The food rate is the number of hares the lynx need to eat to survive. the same time? When there are more lynxes they eat more hares, which decreases the hare population. When the hare population is low, this means less food for the lynxes and results in a decrease in the lynx population. When the lynx population decreases, the hare population increases again, and the up-down cycle continues. If the predator and prey populations are balanced, they will go up and down over time, chasing each other in the circle of life. The question a mathematician asks is, "Can I explain this using addition, subtraction, and multiplication; and can I predict the future populations"

\section{EXPLAINING THE RELATIONSHIP WITH MATHEMATICAL MODELS}

Mathematicians use differential equations and data to describe what they see in the world. The predator-prey relationship was first described using differential equations by two scientists named Lotka [1] and Volterra [2]. They wanted to use mathematics to explain the rise and fall observed in the general predator-prey relationship.

The equations can sometimes look very complicated, but all they are is a way to describe how and why populations change. A famous mathematician named Leonhard Euler (1707-1783) showed that differential equations could just be written as pluses and minuses, with a bit of multiplication. Differential equations can be used to model the populations of lynxes (predators) and hares (prey) using the data from the Hudson Bay Company. We fit the original data using mathematical methods [3], to estimate the values for the growth rate $\left(\boldsymbol{r}_{\text {growth }}\right)$, death rate $\left(\boldsymbol{r}_{\text {death }}\right)$, eaten rate $\left(\boldsymbol{r}_{\text {eaten }}\right)$, and food rate $\left(\boldsymbol{r}_{\text {food }}\right)$, which we will use to predict the hare and lynx populations.

\section{Modelling the Snowshoe Hare Population}

When developing an equation, a mathematician thinks about the world. Now, let us think about what is happening to the hare population over time. If there were no lynxes, then the hare population in the future, $\mathrm{H}_{\mathrm{F}}$, would be equal to the current hare population, $\mathrm{H}_{\mathrm{C}}$, plus births and minus deaths. We call this the growth rate, $r_{\text {growth }}$. The number of births and deaths will depend on the how many hares are alive now, so we multiply $r_{\text {growth }}$ by $\mathrm{H}_{\mathrm{C}}$ (Figure $2 \mathrm{~A}$ ).

Let us use the Hudson Bay data to put numbers into the equation. when the data starts in 1895 , the hare population is 85 , so we will let $\mathrm{H}_{\mathrm{C}}=85$ hares. The growth rate for the hare population is $r_{\text {growth }}=0.9$ in a year. Since $r_{\text {growth }}$ is positive, we expect the future population to grow. This gives the future hare population $\mathrm{H}_{F}$ in 1896:

$H_{F}=H_{C}+\left(r_{\text {growth }} \times H_{C}\right), H_{F}=85+(0.9 \times 85)=161.5$. 
Figure 2

(A) The equations used to predict the future hare population if there were no lynxes, which results in exponential growth. (B) The equations used to predict the future lynx population if there were no hares, resulting in exponential decline. (C) The equations for the hare and lynx populations when the populations are interacting with each other. This results in fluctuating population levels for both hares and lynxes.

\section{EXPONENTIAL}

\section{GROWTH}

Steady and rapid growth.

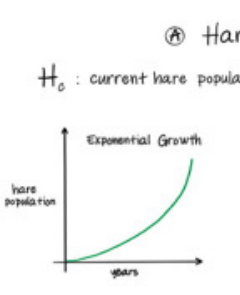

(A) Hare Population

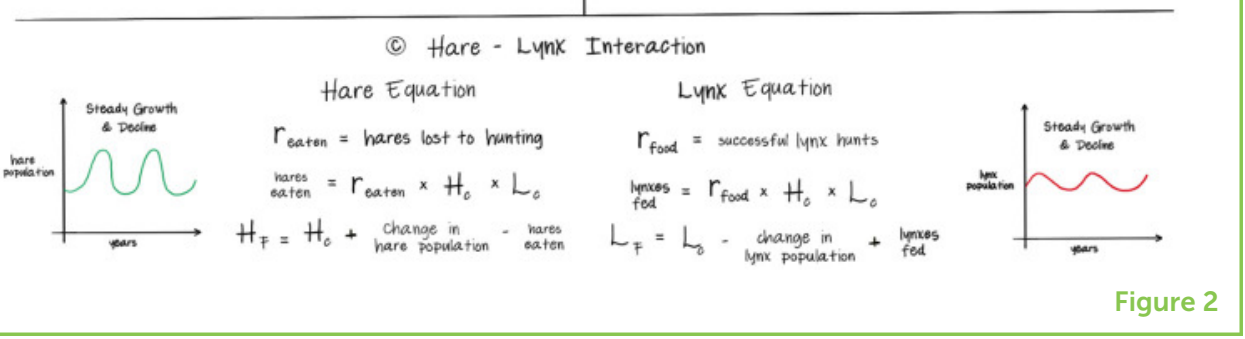

We predict that the future hare population will be 161.5 hares. If the population keeps growing like, this the entire world will be covered in hares, which is called exponential growth (Figure 2A).

\section{Modelling the Snow Lynx Population}

Let us next consider what is happening to the lynx population over time. If there are no hares, the lynxes would have no food, so the lynx population would go down. To model this, we use subtraction. The future number of lynxes $\left(L_{F}\right)$ is equal to the current number of lynxes $\left(L_{C}\right)$ minus the death rate, $r_{\text {death }}$, times the current number of lynxes (Figure 2B).

The lynx population in 1895 is 51 , and by fitting the data we set the death rate to $r_{\text {death }}=0.25$. Now the equation gives:

$L_{F}=L_{C}-\left(r_{\text {death }} \times L_{C}\right)$,

$\mathrm{L}_{\mathrm{F}}=51-(0.25 \times 51)=38.25$

Our calculation predicts the future lynx population in 1896 to be 38.25 lynxes. This is known as exponential decline and, if it keeps happening, there will be no lynxes (Figure 2B).

\section{Modelling the Hare and Lynx Interaction}

On their own, the hare population increases, and the lynx population decreases. What do we know about how these populations interact with each other? Lynxes eat hares and so decrease the hare population; therefore, we use subtraction to model this. We need

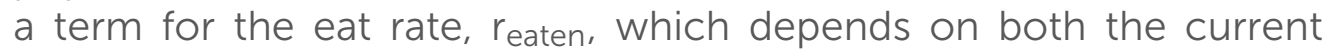
lynx and hare populations available to both eat and be eaten. So, we multiply $r_{\text {eaten }}$ by $L_{C}$ and $H_{C}$. 
Figure 3

Hare and lynx populations modelled using the equations and the Hudson-Bay Company data from 1895 to 1935. (A) The modelled hare population. (B) The modelled lynx population. These two plots show the rise and fall that we saw in the real data in Figure 1. (C) How the lynx population changes for different hare populations. The $x$ is the mean lynx and hare population, which the two populations orbit. The arrows and numbers indicate the calculations in the text, from 1895 to $1896^{2}$

2 Link to animated version of the figure here.
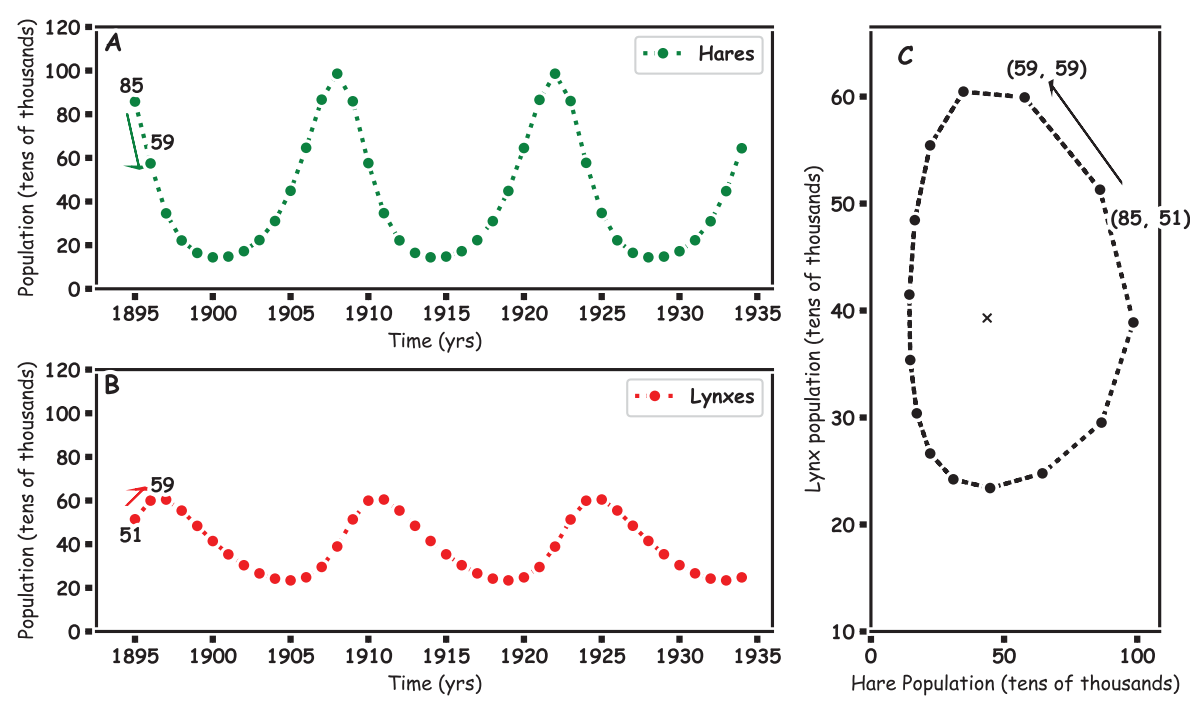

Figure 3

By the same logic, the hares are a food source for the lynxes, so we use addition in the lynx equation and multiply the current hare population by the current lynx population times a food rate, $r_{\text {food }}$ (Figure 2C).

The values of $\mathrm{H}_{C}=85$ hares, $r_{\text {growth }}=0.9, \mathrm{~L}_{C}=51$ lynxes, and the $r_{\text {death }}$ $=0.25$ remain the same. From the data, we get an eat rate of $r_{\text {eaten }}=$ 0.024 and $a$ food rate of $r_{\text {food }}=0.005$. Putting these numbers into the equation for predicting the future number of hares gives:

$\mathrm{H}_{\mathrm{F}}=\mathrm{H}_{\mathrm{C}}+\left(\mathrm{r}_{\text {growth }} \times \mathrm{H}_{\mathrm{C}}\right)-\left(\mathrm{r}_{\text {eaten }} \times \mathrm{L}_{\mathrm{C}} \times \mathrm{H}_{\mathrm{C}}\right)$,

$H_{F}=85+(0.9 \times 85)-(0.024 \times 85 \times 51)=59.24$,

and the equation for predicting the future number of lynxes now gives:

$L_{F}=L_{C}-\left(r_{\text {death }} \times L_{C}\right)+\left(r_{\text {food }} \times L_{C} \times H_{C}\right)$

$L_{F}=51-(0.25 \times 51)+(0.005 \times 51 \times 85)=59.925$

Our model (both equations above) predicts a decrease in the hare population and an increase in the lynx population in 1896, as shown in Figure 3 by the green and red arrows.

To predict how the populations would change in the following year, 1897, we would plug our $H_{F}$ and $L_{F}$ values into $H_{C}$ and $L_{C}$ in the new equations. Each time we do this we get new values, and each value is a point for our graphs in Figure 3. 
EQUILIBRIUM

POINT

The balance point in the two populations. When a system is in equilibrium, we say it is stable.

3 Watch: Sustainable Human 2014.

4 Play here: https:// ecobuildergame.org.

\section{VISUALISING THE PREDATOR PREY-RELATIONSHIP}

Using the equations from above and some computer code [4], we simulate both the hare and lynx populations and make our own data showing how the predator-prey relationship evolves over time (Figure 3).

Another way to show how two species are linked is to plot how the hare population ( $\mathrm{x}$-axis) and lynx population ( $\mathrm{y}$-axis) change in relation to each other (Figure 3C). The $x$ in the middle shows the average hare (39) and average lynx (45) populations, known as the equilibrium point. The lynx and hare populations circle around this average as the populations rise and fall, plotting the circle of life. It looks a bit like the orbit of the earth around the sun. The populations go around and around, which represents their ups and downs over time. In a balanced ecosystem, like the one modelled here, the orbit stays stable; but if it starts spiralling in or out, this could be an early sign of change.

One such change occurred in 1995, when wolves were re-introduced to Yellowstone Park. This lead to some surprising results for the surrounding ecosystem ${ }^{3}$. Based on these amazing observations and mathematics similar to what we have shown here, Goodman and colleagues developed a computer game to build a balanced eco-system ${ }^{4}$.

\section{MODELS ARE NOT EXACT}

When mathematicians try to describe something complicated, they simplify things. The equations we have shown must simplify things, too. The simplifications mean that the predictions and simulations do not perfectly follow the original data. Here is some information we left out of our model:

- There is more than one predator of the snowshoe hare.

- Snow lynxes hunt more than just snowshoe hares; they can also eat fish and squirrels.

- In our model, the snowshoe hares do not run out of food, which is not true in winter.

- What about human fur hunters who hunt both lynxes and hares?

To make the equations work for all these other situations, we would have to include extra equations and more pluses and minuses. If we have all the data, we could perfectly model the future. Even with these simplifications, the mathematics still does a good job modelling the hare and lynx populations. 


\section{HOW ELSE CAN THIS MODEL BE USED?}

If you change the words "snow lynx" to "shark" and "snowshoe hare" to "fish" in this model, the mathematics will still work, with the right data [2]. You could even use the same equations and change the word "lynx" to "zombie" and "hare" to "human"! The predator-prey relationship can be expanded further outside of animal populations and can be used to model how companies interact, how chemical reactions occur, and how viruses spread. You can read more about the mathematics of viruses in another Frontiers for Young Minds paper by clicking here [5].

\section{SUMMARY}

To develop models of the real world, mathematicians need to start with good data. This means it is vital for scientists, conservationists-and even fur hunters!-to collect information from the environment around them. Using data, we can spot patterns in relationships and then use mathematics to recreate these patterns and predict future data that can represent and predict the future of those relationships. These predictions can help us maintain balanced ecosystems. Hopefully, from this article, you can see how all it takes is the basic mathematics of adding, subtracting, and multiplying-and a bit of clever thinking-to model and predict the populations of a predator, its prey, and much more.

\section{ACKNOWLEDGMENTS}

This work was supported by Irish Research Council funding (GOIPG/ 2020/943).

\section{REFERENCES}

1. Lotka, A. J. 1920. Analytical note on certain rhythmic relations in organic systems. Proc Natl Acad Sci USA. 6:410-5.

2. Volterra, V. 1926. Fluctuations in the abundance of a species considered mathematically. Nature. 118:558-60.

3. de Silva, B. M., Champion, K., Quade, M., Loiseau, J. C., Kutz, J. N., and Brunton, S. L. 2020. PySINDy: a python package for the sparse identification of nonlinear dynamics from data. arXiv Preprint arXiv:2004.08424.

4. Butler, J. S., and Brady, R. M. 2020. Predator Prey Code for Young-Minds. GitHub. Available online at: https://github.com/john-s-butler-dit/Predator-Prey-forYoung-Minds

5. Brooks, H. Z., Kanjanasaratool, U., Kureh, Y. H., and Mason. P. 2021. Disease detectives: using mathematics to forecast the spread of infectious diseases. Front Young Minds. 9:577741. doi: 10.3389/frym.2020.577741 
SUBMITTED: 08 January 2021; ACCEPTED: 19 November 2021;

PUBLISHED ONLINE: 24 December 2021.

EDITED BY: Lorelei Koss, Dickinson College, United States

CITATION: Brady RM and Butler JS (2021) The Circle of Life: The Mathematics of Predator-Prey Relationships. Front. Young Minds 9:651131. doi: 10.3389/frym.2021. 651131

CONFLICT OF INTEREST: The authors declare that the research was conducted in the absence of any commercial or financial relationships that could be construed as a potential conflict of interest.

COPYRIGHT (c) 2021 Brady and Butler. This is an open-access article distributed under the terms of the Creative Commons Attribution License (CC BY). The use, distribution or reproduction in other forums is permitted, provided the original author(s) and the copyright owner(s) are credited and that the original publication in this journal is cited, in accordance with accepted academic practice. No use, distribution or reproduction is permitted which does not comply with these terms.

\section{YOUNG REVIEWERS}

\section{GUS, AGE: 11}

Gus likes to play soccer, basketball, and tennis. In the winter, he likes to ski.

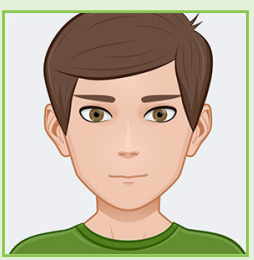

\section{JOSIAH, AGE: 11}

Josiah enjoys cubing, soccer, and playing with his dog, Peppermint. He also likes to read and listen to Harry Potter books. He is still undecided as to whether or not he likes math.

\section{AUTHORS}

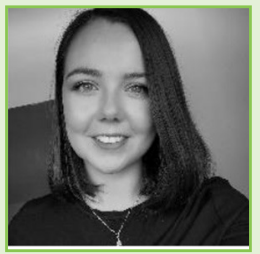

\section{REBECCA M. BRADY}

I am a Ph.D., student of mathematical sciences also based in the Technological University Dublin, Ireland. My research focuses on creating mathematical models to describe how we use sensory information taken in from the world around us. I am particularly interested in how this process differs in people who have problems with their movement, like those with Parkinson's disease. I like to spend my free time reading, creating art, and spending quality time with my family, friends, and my dog, Pippa.

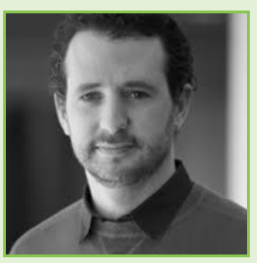

\section{JOHN S. BUTLER}

I am a mathematics lecturer in the Technological University Dublin, Ireland. I use my dual backgrounds in mathematics and neuroscience to design experiments and analysis methods to understand the world using mathematics. I have researched 
how the brain uses vision, touch, hearing, and body motion information for walking, driving, and flying, using robots to fly people through virtual reality. When not teaching or researching, I like to play with my 6-year-old daughter. *John.s.butler@tudublin.ie

${ }^{\dagger}$ These authors have contributed equally to this work 